\title{
Platelet-Activating Factor Antagonist BN 50730 Attenuates Hypoxic-Ischemic Brain Injury in Neonatal Rats
}

\author{
XIAO-HONG LIU, BAIK-LIN EUN, AND JOHN D.E. BARKS \\ Department of Pediatrics, University of Michigan Health System, Ann Arbor, Michigan 48109-0646, \\ U.S.A. [X.-H.L., J.D.E.B.]; and Department of Pediatrics, Ansan Hospital, Korea University Medical \\ Center, Gojan-Dong, Ansan-Si, Kyongki-Do, 425-020, Korea [B.-L.E.]
}

\begin{abstract}
ABST
Platelet-activating factor (PAF) is a lipid derived from break-
down of cell membranes that is postulated to be a mediator of
cerebral ischemic injury. PAF regulates CNS gene transcription
via intracellular binding sites. To test the hypothesis that PAF
mediates CNS injury in part by modulating gene transcription,
we evaluated the neuroprotective efficacy of the drug BN 50730,
an antagonist of the intracellular (microsomal) CNS PAF binding
site, in the neonatal rat model of unilateral cerebral hypoxia-
ischemia. Seven-day-old rats underwent right carotid ligation
followed by a 2.5 -h exposure to $8 \% \mathrm{O}_{2}$, and were then treated
with BN 50730 (2.5 or $25 \mathrm{mg} / \mathrm{kg}$ per dose) or vehicle, at 0 and
$2 \mathrm{~h}$ after the end of hypoxia. Ipsilateral cortical, striatal, and
hippocampal damage was quantitated either $5 \mathrm{~d}$ later, or at 5 wk
after the insult. Treatment with BN 50730 resulted in approxi-
\end{abstract}
PAF (1-O-alkyl-2-acetyl-sn-glycero-3-phosphocholine) is a potent phospholipid mediator with distinct systemic and CNS actions. In the CNS, PAF is synthesized in neurons and microglia $(1,2)$, and PAF receptors are expressed predominantly in neurons and microglia and, to a lesser extent, on astrocytes and CNS endothelium (3-5). PAF has distinct neuronal actions, as a synaptic messenger, a transcriptional activator, and a critical determinant of normal brain development $(6,7)$. In addition to these CNS effects, PAF has potent proinflammatory systemic effects (8). PAF accumulates in ischemic CNS tissue in mature and immature animals (9-12). In mature animals, most reports indicate that PAF receptor antagonist treatment attenuates cerebral ischemic damage (13-16). Several recent studies implicate PAF as a mediator of ischemic injury in the neonatal brain $(12,17)$.

Received January 20, 2000; accepted December 13, 2000.

Correspondence and reprint requests: John D.E. Barks, M.D., Room 8301 MSRB III, Box 0646, University of Michigan Health System, 1150 W. Medical Center Drive, Ann Arbor, MI 48109-0646, U.S.A.; e-mail: jbarks@umich.edu

Supported by the United Cerebral Palsy Research and Education Foundation (grant R-608-97), American Heart Association-Michigan Affiliate Grant-in-Aid (08GS9789), and by the National Institutes of Health (grant NS 37036).

Current address (X-H.L.): Parke-Davis Pharmaceuticals, R187C/Building 20, ParkeDavis Pharmaceuticals, 2800 Plymouth Road, Ann Arbor, MI 48105, U.S.A. mately $60-80 \%$ reduction in ipsilateral tissue loss at both times. Learning and memory were evaluated $5 \mathrm{wk}$ after insult using the Morris Watermaze place navigation task. Severity of cortical and striatal damage correlated significantly with learning and memory deficits. These results support the hypothesis that PAF is a pathogenetic mediator of hypoxic-ischemic damage in the immature brain. Accumulating evidence suggests that PAF mediates its deleterious effects in the immature CNS via multiple mechanisms. (Pediatr Res 49: 804-811, 2001)
PAF, platelet-activating factor
P12, postnatal d 12

Brain PAF concentrations rise acutely after neonatal cerebral hypoxia-ischemia (12), most likely as a result of breakdown of membrane phospholipids. Treatment with the PAF receptor antagonist BN 52021 (ginkgolide B), beginning either before or immediately after hypoxia exposure, reduced hypoxicischemic brain injury in postnatal d 7 rats (17). Pretreatment with a Ginkgo biloba extract, which includes BN 52021, attenuated posthypoxic-ischemic PAF accumulation (12). These results suggest that PAF contributes to the pathogenesis of neonatal cerebral hypoxic-ischemic injury.

PAF could mediate cerebral hypoxic-ischemic injury via either of two distinct neuronal PAF binding sites. Studies in adult rat cerebral cortex subcellular membrane fractions delineate distinct populations of neuronal PAF binding sites in synaptic membranes versus intracellular (microsomal) membranes (18). These studies suggest that BN 52021 is a noncompetitive antagonist of synaptic cell membrane PAF binding sites, and is a more potent antagonist of synaptic sites than microsomal PAF binding sites. In contrast, the hetrazepine BN 50730 [tetrahydro-4,7,8,10 methyl-1(chloro-2 phenyl)6(methoxy-4 phenyl-carbamoyl)-9 pyrido $\left.4^{\prime}, 3^{\prime}, 4,5\right)$ thieno $[3,2-f]$ triazolo- $1,2,4[4,3-a]$ diazepine- 1,4 is a competitive 
antagonist of the intracellular (microsomal) population of PAF binding sites, but not of synaptic membrane sites. Activation of these two distinct populations of neuronal PAF binding sites results in different cellular actions. Presynaptic cell membrane PAF receptor activation augments excitatory amino acidmediated neurotransmission and results in increased intracellular calcium concentrations (6). Activation of the intracellular (microsomal) PAF receptor results in induction of immediateearly genes (e.g. fos, jun, zif/268, COX-2), suggesting a role in transcriptional regulation (6). BN 50730 blocks the induction of immediate-early genes by PAF in vitro and by electroconvulsive and kainic acid-induced seizures in vivo (6).

There is growing epidemiologic and experimental evidence that inflammatory mediators play a pathophysiologic role in neonatal brain injury, including injury induced by cerebral hypoxia-ischemia $(19,20)$. Systemically PAF has potent proinflammatory effects on leukocytes, including stimulation of cytokine production (8); these effects could also contribute to CNS damage in cerebral hypoxia-ischemia. PAF could mediate hypoxic-ischemic brain damage via microglial PAF receptors (3). Microglia are the resident inflammatory cells of the CNS, and may play a role in brain injury by releasing a variety of toxins, e.g. eicosanoids, nitric oxide, or proinflammatory cytokines (21). PAF stimulates, and the PAF receptor antagonist BN 52021 attenuates, microglial production of nitric oxide and the proinflammatory cytokines IL- $1 \beta$ and tumor necrosis factor- $\alpha$ (22). The effect of BN 50730 on microglial PAFmediated events is unknown. At the intracellular level, PAF stimulates both calcium accumulation and immediate-early gene expression in microglia (23). Thus BN 50730 might be expected to block PAF-induced changes in gene transcription in microglia, as has already been demonstrated in neurons.

Previous studies suggest that at least some of the deleterious effects of PAF in neonatal cerebral hypoxia-ischemia are mediated via the synaptic membrane PAF receptor (17). The present study was designed to test the hypothesis that PAF could also mediate hypoxic-ischemic brain damage via the microsomal PAF binding site. Specifically, we hypothesized that blockade of microsomal PAF binding sites by BN 50730 would attenuate hypoxic-ischemic brain injury in neonatal rats. We evaluated hypoxic-ischemic damage at both $5 \mathrm{~d}$ and $5 \mathrm{wk}$ of recovery to demonstrate that neuroprotection by BN 50730 was sustained and that treatment did not simply delay the ultimate manifestation of injury (24).

\section{METHODS}

Hypoxia-ischemia. We used a well-characterized model of unilateral cerebral hypoxia-ischemia in postnatal d 7 rats, induced by unilateral carotid ligation followed by timed exposure to a hypoxic inspiratory gas mixture $\left(8 \% \mathrm{O}_{2}\right)(25)$. In this model, the severity of injury is directly related to the duration of hypoxic exposure (26). We used conditions resulting in moderate to severe damage to ipsilateral cortex, striatum, and hippocampus; typical histopathologic findings $5 \mathrm{~d}$ after lesioning included regional atrophy and infarction. In this model, ipsilateral cerebral blood flow is dramatically reduced during the hypoxic exposure, but returns to normal for $\geq 24 \mathrm{~h}$ after the end of hypoxic exposure (27). Thus, this model incorporates both focal cerebral ischemia and reperfusion. Although precise comparisons with human CNS development are difficult, brains of 7-d-old rats are similar to the brains of third trimester human fetuses (and thus premature infants) by a variety of indices (28-30). Postnatal d 7 unsexed Sprague Dawley rat pups (Charles River Laboratories, Wilmington, MA, U.S.A.) $(n=$ 68) underwent right carotid ligation under methoxyflurane anesthesia, followed $1 \mathrm{~h}$ later by $2.5 \mathrm{~h}$ of exposure to $8 \% \mathrm{O}_{2}$ (balance nitrogen), in $500-\mathrm{mL}$ glass chambers partially immersed in a $38^{\circ} \mathrm{C}$ water bath. All study methods were approved by the University Committee on Use and Care of Animals, and all efforts were made to minimize the number of animals used.

Drug treatment. In four independent experiments, two serial doses of BN 50730, either $2.5 \mathrm{mg} / \mathrm{kg}$ per dose $(n=13)$ or 25 $\mathrm{mg} / \mathrm{kg}$ per dose $(n=12)$, or vehicle $(5 \%$ gum arabic in water; $n=21$ ) were administered by midline subumbilical i.p. injection immediately and again $2 \mathrm{~h}$ after the end of hypoxic exposure. The dose range chosen was based on reports in which BN 50730 in similar doses was found to alter learning and memory or affect immediate-early gene expression in rodents $(31,32)$. In these four experiments, the severity of brain injury was evaluated $5 \mathrm{~d}$ after the hypoxic-ischemic episode. In one subsequent experiment, serial doses of BN $50730(25 \mathrm{mg} / \mathrm{kg}$ per dose; $n=8)$ or vehicle $(n=5)$ were administered by i.p. injection immediately and $2 \mathrm{~h}$ after the end of hypoxic exposure, and outcome was evaluated at approximately 6 wk of age to confirm whether neuroprotective effects detected $5 \mathrm{~d}$ after the insult were sustained. In all experiments, after a 15 -min. recovery period in a $37^{\circ} \mathrm{C}$ heated air incubator, animals were returned to the dam. In the long-term outcome studies, pups were weaned on postnatal d 22, and housed in separate-sex cages until the time of behavioral testing in the Morris Watermaze and subsequent killing at 2 mo of age. BN 50730 was a gift from Dr. N. Bazan (Louisiana State University Neuroscience Center, New Orleans, LA, U.S.A.). The structure of this hetrazepine compound has been published by other investigators (33).

In one experiment, in which two doses of BN 50730 (25 $\mathrm{mg} / \mathrm{kg}$ per dose; $n=5)$ or vehicle $(n=5)$ were administered immediately and again $2 \mathrm{~h}$ after the end of hypoxic exposure, esophageal temperature was measured at $5,15,30,60$, and 120 min after the end of hypoxic exposure, using a $0.6-\mathrm{mm}-$ diameter flexible probe, inserted orally to a depth of $3 \mathrm{~cm}$ (YSI thermometer 43TA with probe 554, Yellow Spring Instruments, Yellow Springs, OH, U.S.A.).

Neuropathology. After hypoxic-ischemic lesioning, either on P12 (four experiments) or at approximately $6 \mathrm{wk}$ of age (one experiment), rats were killed and brains frozen under powdered dry ice. Twenty-micrometer coronal sections, postfixed in paraformaldehyde vapor, were stained with cresyl violet and analyzed morphometrically, using National Institutes of Health Image software (NIH Image version 1.61, National Institutes of Health, Bethesda, MD, U.S.A.). To quantify injury severity in the P12 brains, bilateral crosssectional areas of neocortex, striatum, and dorsal hippocampus were measured in regularly spaced sections from the level of the anterior genu of the corpus callosum to the posterior genu 
of the corpus callosum (an average of 20 sections/brain). Regional volumes were estimated by summating areas and multiplying by the distance between sections (34). Neocortical and striatal areas measured included only tissue with intact Nissl staining. Hippocampal areas measured included the entire structure because there was no clear demarcation between intact and nonintact tissue, based on staining characteristics. The hypoxic-ischemic insult occurs during a period of rapid brain growth. Thus, regional atrophy evolves in damaged brain tissue by $3-5 \mathrm{~d}$ after the initial insult, and regional volumes are an accurate reflection of the severity of brain damage $(26,35)$. Four P12 brains were excluded from morphometric analysis because of technical problems encountered during sectioning (three cases, BN $507302.5 \mathrm{mg} / \mathrm{kg}$; one case, BN 5073025 $\mathrm{mg} / \mathrm{kg}$ ). To quantify injury severity in the young adult brains, bilateral cross-sectional areas of neocortex, striatum, and dorsal hippocampus were measured in six standardized sections (Paxinos and Watson panels 13, 17, 18, 21, 22, and 23) (36). This approach provided greater representation of the substantial volume of damaged tissue that we observed caudal to the posterior genu of the corpus callosum in these older survivors of neonatal hypoxia-ischemia than did the approach used in the P12 brains.

Cognitive testing. In the long-term outcome experiment, we also evaluated the effect of neonatal BN 50730 treatment on posthypoxic-ischemic cognitive function, using the Morris Watermaze place navigation task (37). We added this functional measure to determine whether reduction in damage resulted in an improvement in function, an important issue in clinical and preclinical studies. To evaluate learning, on five successive days, beginning on d 35 of life, rats were positioned randomly in each of four quadrants, facing the outside of a 180-cm-diameter circular pool filled with room temperature water, for four successive trials per day. Swimming escape latency (seconds) to a hidden Plexiglas platform in a fixed location $1.5 \mathrm{~cm}$ beneath the surface was recorded; we placed the rats on the platform if they were unsuccessful after $120 \mathrm{~s}$. Rats were left on the platform for $30 \mathrm{~s}$ between trials. Skim milk powder was added to the water to render the platform invisible. The pool was surrounded by multiple visual landmarks whose location relative to the pool did not change between testing days. Testing occurred at the same time and under the same lighting conditions every day. On the fifth day, after the completion of training the platform was removed, and short-term retention was tested with a transfer test, i.e. a 2-min swim, recording time (seconds) spent in the quadrant formerly occupied by the platform. On the sixth day, to evaluate longterm retention, an additional transfer test was performed.

Data analysis. Preliminary descriptive statistics indicated that there was considerable variability in morphometric indices of injury within treatment groups. Thus cortical, striatal, and hippocampal volumes were compared among treatment groups by Mann-Whitney or Kruskal-Wallis nonparametric tests. Percent regional damage, or percent reduction in regional volume, ipsilateral to carotid ligation, i.e. percent left-right (L-R) difference in volumes $[100 \times(\mathrm{L}-\mathrm{R}) / \mathrm{L}]$, was also compared among groups independently for each of the three regions evaluated by nonparametric tests. The significance of between- subgroup differences was evaluated using Dunn's post hoc test for the Kruskal-Wallis nonparametric test. To evaluate the magnitude of the protective effect of BN 50730 rescue treatment on the severity of brain damage, percent protection was calculated based on comparison of the median percent damage in BN 50730-treated animals and controls, using the formula $100 \times[1-(\%$ damage drug-treated / \% damage controls $)]$ (35). Serial posthypoxic-ischemic esophageal temperatures were compared among drug-treated and control animals by repeated measures ANOVA. Mean daily escape latency during the $5 \mathrm{~d}$ of training in the Morris Watermaze place navigation task was compared among groups by repeated measures ANOVA. To determine whether lesion severity influenced learning, independent of drug treatment, we calculated the correlation between percent striatal, hippocampal, and cortical damage and both daily mean escape latencies and the sum of all latencies during $5 \mathrm{~d}$ of training. The relationship between percent striatal, hippocampal, and cortical damage and sum of all latencies during $5 \mathrm{~d}$ of training was also evaluated by stepwise linear regression, with damage percentages as the independent variables. Short- and long-term memory retention was evaluated by between-group comparison of the time spent in the quadrant formerly occupied by the platform, using parametric and nonparametric tests. Statistical analysis was performed using microcomputer statistical software packages (Statview 4.57, Abacus Concepts, Berkeley, CA, U.S.A.; Systat 5.2, Systat Inc., Evanston IL, U.S.A.).

\section{RESULTS}

In vehicle-treated rats, the experimental conditions $(2.5 \mathrm{~h}$ of unilateral cerebral hypoxia-ischemia) resulted in moderately severe brain damage when evaluated at either $5 \mathrm{~d}$ after insult or 5 wk later. Typical histopathologic findings $5 \mathrm{~d}$ after insult included cortical infarction with cavitation, and striatal and hippocampal infarction or atrophy (Fig. 1). Mortality during and after hypoxia-ischemia did not differ between the $\mathrm{BN}$ 50730 -treated ( 3 of 37) and control groups (3 of 31). The time course of posthypoxic-ischemic esophageal temperatures was stable, and similar in the drug-treated and control animals.

Treatment with BN 50730 resulted in a reduction in ipsilateral brain damage evaluated $5 \mathrm{~d}$ after the unilateral cerebral hypoxic-ischemic episode. Treatment with BN 50730 (25 $\mathrm{mg} / \mathrm{kg}$ per dose), initiated immediately after the end of hypoxic exposure, resulted in attenuation of ipsilateral damage in cortex, striatum, and hippocampus (Figs. 1 and 2). However, rescue treatment with the lower BN 50730 dose $(2.5 \mathrm{mg} / \mathrm{kg}$ per dose) did not result in a significant reduction in ipsilateral brain damage (Fig. 2). The cortical damage in the drug-treated groups appeared to be dichotomous, with either mild $(<25 \%)$ or severe $(>70 \%)$ tissue loss. However, even when cortical damage was reanalyzed dichotomously ( $\leq 50 \%$ damage versus $>50 \%$ damage), only treatment with the higher dose provided significant neuroprotection ( $>50 \%$ damage: control, 16 of 19 ; versus BN $507302.5 \mathrm{mg} / \mathrm{kg}$ per dose, 4 of 8; NS, Fisher's exact test; versus BN $5073025 \mathrm{mg} / \mathrm{kg}$ per dose, 4 of $10 ; p<$ 0.05 , Fisher's exact test). In comparison to vehicle-injected controls, the median percent protection, a measure of reduction 
BN $50730(25 \mathrm{mg} / \mathrm{kg} / \mathrm{dose})$

A

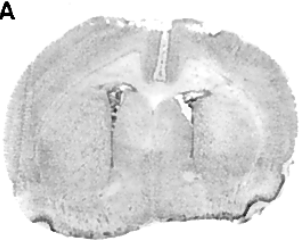

B

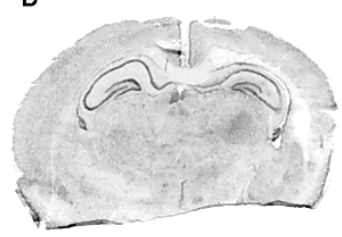

$-1 \mathrm{~mm}$

Figure 1. Posthypoxic-ischemic treatment with the PAF antagonist BN 50730 attenuates cortical, striatal, and hippocampal damage $5 \mathrm{~d}$ after insult. Cresyl violet-stained sections from two representative P12 rats, $5 \mathrm{~d}$ after induction of right-sided cerebral hypoxia-ischemia by right carotid ligation, followed by a 2.5-h exposure to $8 \% \mathrm{O}_{2} . A$ and $B$, rat treated with $\mathrm{BN} 5073025 \mathrm{mg} / \mathrm{kg}$ per dose 0 and $2 \mathrm{~h}$ after the end of hypoxia; $C$ and $D$, vehicle-treated control. In $C$ and $D$ note right cortical infarction (arrowheads), striatal atrophy and pallor $(*)$, and hippocampal atrophy and pyramidal cell loss (arrow). Scale bar $=1$ $\mathrm{mm}$.

in injury severity by drug treatment, in animals treated with the higher BN 50730 dose $(25 \mathrm{mg} / \mathrm{kg})$ was $71 \%, 57 \%$, and $63 \%$ in cortex, striatum, and hippocampus, respectively.

The neuroprotective efficacy of posthypoxic-ischemic rescue treatment with BN 50730 was confirmed by morphometric analysis of brain sections from 6-wk-old rats that underwent neonatal cerebral hypoxia-ischemia at $7 \mathrm{~d}$ of life, followed by treatment with BN $50730(25 \mathrm{mg} / \mathrm{kg}$ per dose) (Figs. 3 and 4). In vehicle-treated rats evaluated $5 \mathrm{wk}$ after hypoxic-ischemic lesioning, the pattern of injury was different from that at $5 \mathrm{~d}$ after lesioning. At this later developmental stage, ipsilateral striatal atrophy was not pronounced, cortex at the level of the striatum tended to be either intact or thinned, with a columnar pattern of neuronal loss, and cortical cavitation or severe atrophy was usually evident only at a more caudal level over the dorsolateral and posterior hippocampus. Within the hippocampus, the rostral pole tended to be most severely atrophied or absent, with some atrophy but structural preservation ventral and posterior (Fig. 3). Compared with concurrent vehicle-injected controls, ipsilateral brain damage was attenuated in cortex and striatum in young adult rats that had received posthypoxic-ischemic treatment with BN 50730 (Fig. 4). In comparison to vehicle-injected controls, the median percent protection, a measure of reduction in injury severity by drug treatment, in animals treated with BN $50730(25 \mathrm{mg} / \mathrm{kg}$ per dose) was $85 \%$ in cortex and $76 \%$ in striatum. When examined at this later time, attenuation of hippocampal damage could not be detected.

When performance was evaluated in the place navigation task beginning on $\mathrm{d} 35$, mean daily escape latencies in the $\mathrm{BN}$ 50730-treated group were lower than in controls for all $5 \mathrm{~d}$ of training; however, the difference between groups was not statistically significant (Table $1, p=0.14$, repeated measures
Cortex

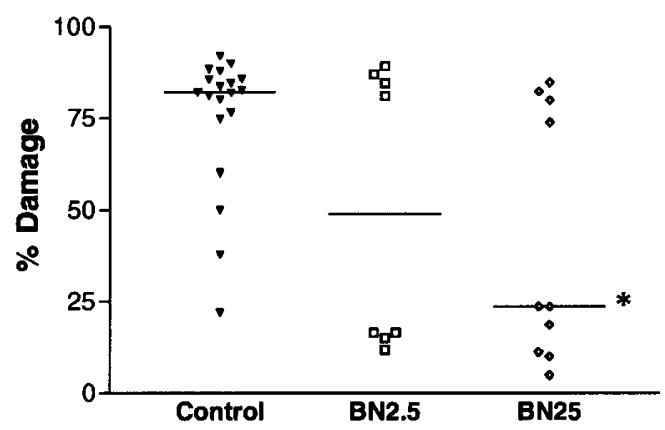

\section{Striatum}

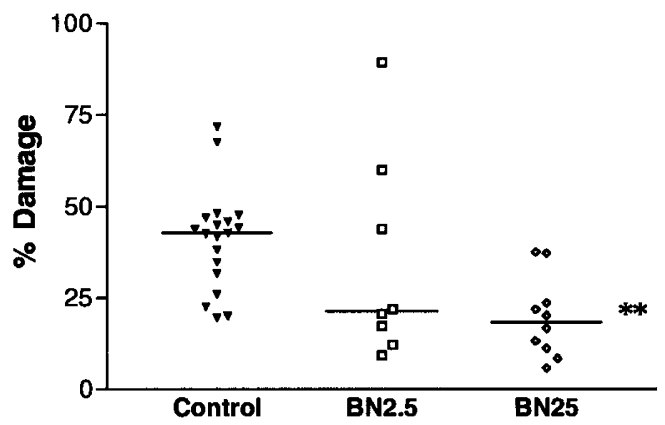

Hippocampus

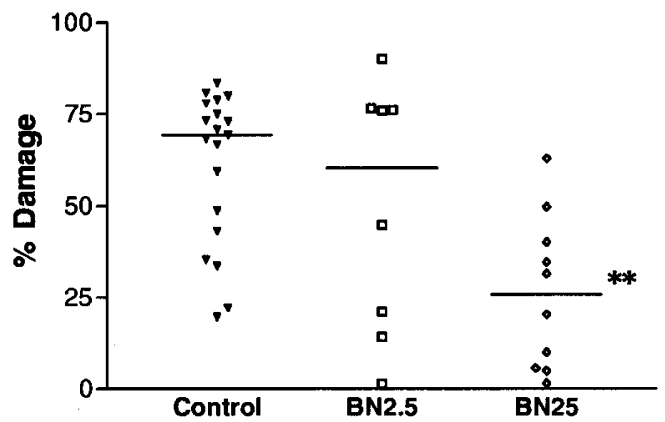

Figure 2. Posthypoxic-ischemic treatment with the PAF antagonist BN 50730 attenuates cortical, striatal, and hippocampal damage $5 \mathrm{~d}$ after insult. Sevenday-old rats underwent unilateral carotid ligation followed by a 2.5 -h exposure to $8 \% \mathrm{O}_{2}$. Immediately after the end of hypoxic exposure, rats received two serial i.p. doses of BN 50730 , either 2.5 or $25 \mathrm{mg} / \mathrm{kg}$ per dose (BN2.5 or $\mathrm{BN} 25$ ), or vehicle (Control) $2 \mathrm{~h}$ apart. Cortical, striatal, and dorsal hippocampal volumes were estimated on P12 from regional area measurements in evenly spaced coronal sections (see Methods), and percent damage (i.e. left-right percent difference was compared among groups by the Kruskal-Wallis nonparametric test, with Dunn's post hoc test of between-subgroup differences $(* p$ $<0.05 ; * * p<0.01$ ). All data points are plotted, with horizontal bars representing median values.

ANOVA). Although an improvement in performance in the BN 50730-treated group could not be demonstrated, when both the controls and the BN 50730-treated rats were combined, there was a significant linear relationship between the severity of brain damage and escape latencies. The correlation between percent cortical damage or percent striatal damage and the sum 
BN $50730(25 \mathrm{mg} / \mathrm{kg} /$ dose $)$

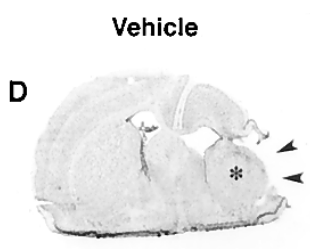

B
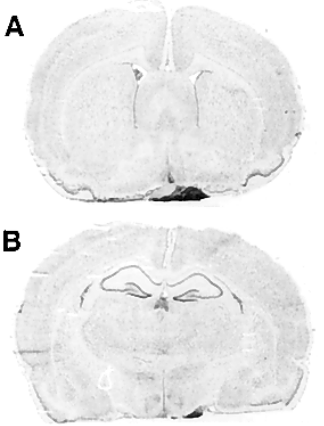

C

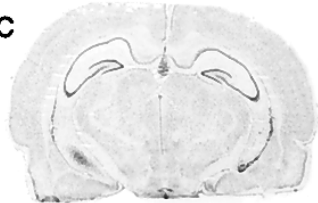
Figure 3. Posthypoxic-ischemic treatment with the PAF antagonist BN 50730
attenuates cortical, striatal, and hippocampal damage $5 \mathrm{wk}$ after insult. Cresyl violet-stained sections from two representative 6-wk-old rats, 5 wk after induction of right-sided cerebral hypoxia-ischemia by right carotid ligation, followed by a 2.5 -h exposure to $8 \% \mathrm{O}_{2} . A-C$, rat treated with $\mathrm{BN} 5073025$ $\mathrm{mg} / \mathrm{kg}$ per dose 0 and $2 \mathrm{~h}$ after the end of hypoxia; $D-F$, vehicle-treated control. In $D-F$ note right cortical cavitation (arrowheads). In addition, note right striatal atrophy in $D(*)$ and right hippocampal atrophy in $E$ and $F$ (arrow). Scale bar $=1 \mathrm{~mm}$.

of escape latencies during the $5 \mathrm{~d}$ of training was statistically significant (cortical, $r=0.683, p=0.01$, Fig. 5; striatal, $r=$ $0.60, p=0.03)$. When individual days were examined, there was a significant correlation $(p \leq 0.05)$ between percent cortical damage and mean daily escape latency on $\mathrm{d} 1,4$, and 5 , and between percent striatal damage and mean daily escape latency on $\mathrm{d} 2$ and 4 . No association was detected between the percent hippocampal damage and escape latencies. In an effort to determine whether damage to different regions contributed independently to the prolongation of escape latencies associated with hypoxic-ischemic damage, stepwise linear regression was performed. This analysis indicated that although there was a significant association between both cortical and striatal damage and prolonged escape latencies, cortical damage made the greatest contribution (multiple $R^{2}=0.466 ; p=0.01$ ), and striatal damage did not make any additional contribution.

When retention was evaluated using both short-term (d 5) and long-term (d 6) transfer tests, there was no improvement in retention in the BN 50730-treated group, compared with controls. Although a significant improvement in retention in the BN 50730-treated group could not be demonstrated, when both the controls and the BN 50730-treated rats were combined, there was a linear relationship between the severity of cortical damage and impaired short-term retention. Increasing cortical percent damage (i.e. increasing severity of damage) was associated with decreased short-term retention $(r=0.553, p=$ $0.05)$. The association between percent cortical damage and long-term retention was weaker $(r=0.491, p=0.09)$. No correlation was detected between the severity of striatal or hippocampal damage and either short- or long-term retention.

\section{Cortex}

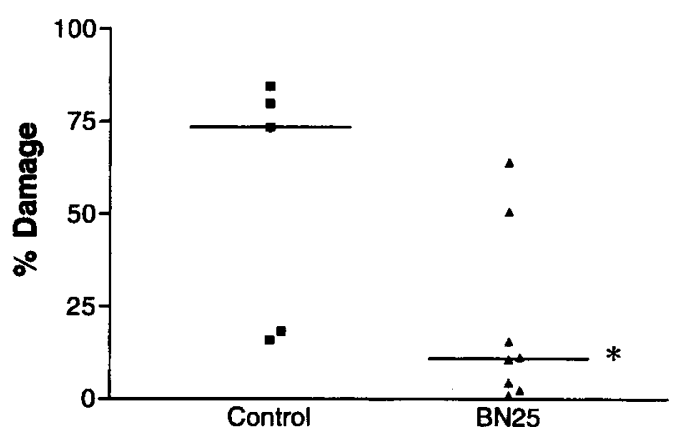

Striatum

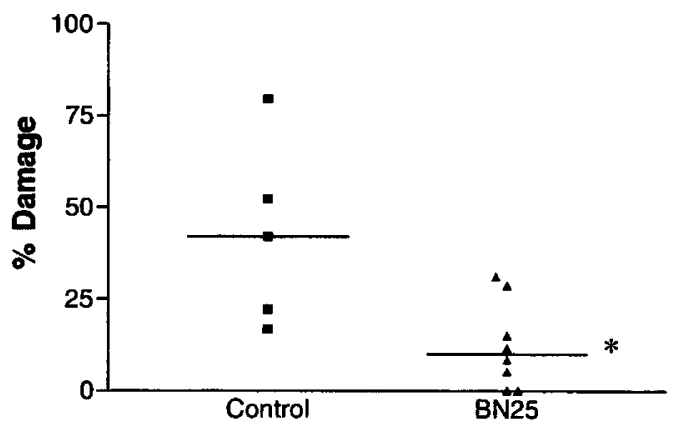

Hippocampus

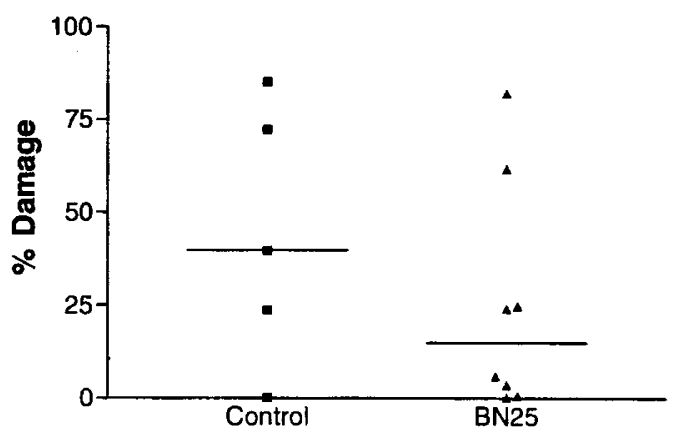

Figure 4. Posthypoxic-ischemic treatment with the PAF antagonist BN 50730 attenuates cortical, striatal, and hippocampal damage $5 \mathrm{wk}$ after insult. Sevenday-old rats underwent unilateral carotid ligation followed by a 2.5-h exposure to $8 \% \mathrm{O}_{2}$. Immediately after the end of hypoxic exposure, rats received two serial i.p. doses of BN $5073025 \mathrm{mg} / \mathrm{kg}$ per dose (BN25) or vehicle (Control) $2 \mathrm{~h}$ apart. Bilateral cortical, striatal, and dorsal hippocampal areas were measured in six standardized coronal sections per brain, and percent damage (i.e. left-right percent difference in regional areas) was calculated $5 \mathrm{wk}$ later (see Methods) and compared between groups by the Mann-Whitney nonparametric test. Cortical and striatal damage was attenuated in the BN 50730treated group $(* p<0.05)$. No effect on hippocampal damage was detected. All data points are plotted, with horizontal bars representing median values.

\section{DISCUSSION}

These results, demonstrating the neuroprotective efficacy of the PAF receptor antagonist BN 50730 in neonatal rats that underwent unilateral cerebral hypoxic-ischemic lesioning, provide additional support for the hypothesis that PAF is a medi- 
Table 1. Evaluation of learning and memory after posthypoxic-ischemic treatment with BN 50730*

\begin{tabular}{|c|c|c|c|c|c|c|c|c|}
\hline \multirow[b]{2}{*}{ Group } & \multirow[b]{2}{*}{$n$} & \multicolumn{5}{|c|}{ Escape latency $\dagger(\mathrm{s}$, mean $\pm \mathrm{SD})$} & \multicolumn{2}{|c|}{$\begin{array}{c}\text { Retention } \ddagger \\
(\mathrm{s}, \text { mean } \pm \mathrm{SD})\end{array}$} \\
\hline & & d 1 & d 2 & d 3 & d 4 & d 5 & d 5 & d 6 \\
\hline Control & 5 & $108 \pm 28$ & $93 \pm 39$ & $90 \pm 25$ & $72 \pm 41$ & $63 \pm 44$ & $39 \pm 19$ & $32 \pm 5$ \\
\hline BN 50730 & 8 & $100 \pm 18$ & $67 \pm 34$ & $59 \pm 37$ & $38 \pm 30$ & $40 \pm 29$ & $42 \pm 17$ & $41 \pm 12$ \\
\hline
\end{tabular}

* Postnatal d 7 rats underwent right carotid ligation followed by a 2.5 -h exposure to $8 \% \mathrm{O}_{2}$. Immediately, and again $2 \mathrm{~h}$ after hypoxia-ischemia, rats received an i.p. injection of BN $50730(25 \mathrm{mg} / \mathrm{kg})$ or an equal volume of vehicle (5\% gum arabic). Rats underwent testing of learning and memory in the Morris Watermaze place navigation task beginning on d 35 of life (see Methods).

$\dagger$ Swimming escape latency (seconds) to a hidden platform was recorded for four successive trials per day per animal, for 5 consecutive days; animals were placed on the platform if they were unsuccessful after $120 \mathrm{~s}$ (see Methods).

$\ddagger$ During a single 2-min free swim with the platform removed, cumulative time (seconds) spent in the quadrant formerly occupied by the platform was recorded, both on $\mathrm{d} 5$, after the completion of training, and again $24 \mathrm{~h}$ later on $\mathrm{d} 6$ (see Methods).

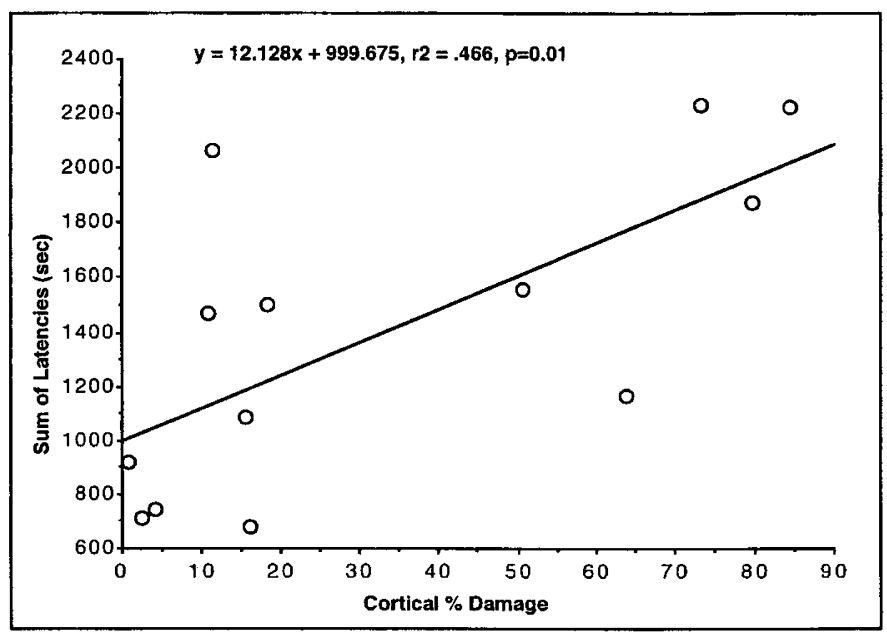

Figure 5. Correlation between severity of cortical damage and learning impairment. Seven-day-old rats underwent unilateral carotid ligation followed by a 2.5 -h exposure to $8 \% \mathrm{O}_{2}$. Immediately after the end of hypoxic exposure, rats received two serial i.p. doses of BN $5073025 \mathrm{mg} / \mathrm{kg}$ per dose or vehicle $2 \mathrm{~h}$ apart. Beginning on d 35 of life, animals underwent testing of learning in the Morris Watermaze place navigation task for four trials per day for five consecutive days (see Methods). Escape latencies during the entire training period were summated; a longer escape latency sum signifies slower learning. After the completion of testing, bilateral cortical areas were measured in six standardized coronal sections per brain, and percent damage (i.e. left-right percent difference in regional areas) was calculated at 6 wk of age (see Methods). There was a significant linear correlation between the severity of cortical damage and learning impairment $(r=0.683, p=0.01)$.

ator of hypoxic-ischemic damage in the immature brain. This hypothesis is also supported by our previous work, in which treatment with the chemically distinct PAF receptor antagonist BN 52021 resulted in a decrease in severity of hypoxicischemic damage (17). Furthermore, the neuroprotective effect of neonatal treatment with BN 50730 persisted into adulthood, indicating that $\mathrm{BN} 50730$ reduced brain damage, rather than simply delaying the ultimate expression of injury. Our initial choice of a posthypoxic-ischemic BN 50730 rescue treatment regimen was influenced both by its relevance to clinical practice and by our previous experience with BN 52021 treatment, in which a rescue regimen was also neuroprotective (17).

It is unclear whether the neuroprotective efficacy of BN 50730 was dose dependent. At the higher dose, which inhibits immediate-early gene induction in rodents, neuroprotection was demonstrated. At the lower dose, which can impair learn- ing and memory in adult rodents, effective neuroprotection could not be demonstrated on evaluation $5 \mathrm{~d}$ after insult. The data in the low-dose treatment group were not normally distributed; thus it is possible that our sample size was too small to detect a real treatment effect in some regions.

Although damage was attenuated in all regions examined when the efficacy of BN 50730 was evaluated 5 d after lesioning, only attenuation of cortical and striatal damage could be demonstrated when evaluation was delayed until $6 \mathrm{wk}$ of age. When the efficacy of neonatal BN 50730 treatment was evaluated in adulthood, no neuroprotective effect could be demonstrated for hippocampus. Other investigators reported similar neuropathologic findings at $6 \mathrm{wk}$ after hypoxiaischemia, and also reported apparent regional differences in neuroprotective efficacy between similar end points (38). Although this discrepancy could be the result of differences in mechanisms and evolution of damage between regions, it is also possible that our sample size may have been inadequate to detect real effects in the hippocampus at the later evaluation time, and that inconsistency in drug delivery may have contributed to variability in the damage seen in the drug-treated group. BN 50730 dissolves poorly in water, thus we administered it as a suspension in a gum arabic solution. We chose not to solubilize the drug in DMSO, to avoid any possible confounding effect of this vehicle (39).

Although BN 50730 treatment attenuated hypoxic-ischemic brain damage, we were unable to detect an improvement in learning or memory in the BN 50730-treated rats, evaluated in the Morris Watermaze place navigation task. Although the mean daily escape latencies were consistently lower in the drug-treated group than in controls, the standard deviations were large. Multiple factors could have contributed to this high variability, including the known heterogeneity of damage in this model, inconsistencies in drug delivery, and variability of the behavioral testing method. Thus it is possible that our sample size was too small to detect a real beneficial effect of BN 50730 treatment on learning and memory. Further behavioral studies were not possible owing to insufficient drug supply. Even though we could not detect an effect of drug treatment on learning and memory, when we combined both the drug-treated and control animals, there was a clear linear correlation between the severity of cortical and striatal damage and impairment of learning. This finding is consistent with the reported linear correlation between sensorimotor performance 
at $6 \mathrm{wk}$ and infarct volume after neonatal cerebral hypoxiaischemia (38). Although the place navigation task is often thought of as a test of hippocampal function, there is evidence that it is also sensitive to neocortical damage (40). Our findings suggest that larger numbers of animals will be needed to detect behavioral evidence of neuroprotection than are typically needed to detect pathologic evidence of neuroprotection. For example, on the basis of the mean escape latencies and standard deviations on d 3 of training, a sample size of nine per group would have been necessary to detect a significant between-group difference in escape latencies on that day $(\alpha=$ $0.05, \beta=0.80)$.

Although these data and our previous report support a role for PAF as a mediator of cerebral hypoxic-ischemic damage, they also suggest that PAF may contribute to the evolution of brain damage by multiple mechanisms. BN 52021 is a selective antagonist of synaptic PAF receptors on neurons, but $\mathrm{BN}$ 50730 antagonizes a microsomal PAF binding site. The fact that treatment with both antagonists reduces hypoxic-ischemic brain damage suggests that the CNS toxicity of PAF is mediated by at least two distinct mechanisms, altered excitatory transmission and altered neuronal gene transcription (6). It is possible that some of the effects of PAF in cerebral ischemia may relate to proinflammatory activity, for example activation of microglia (3). A PAF antagonist might indirectly influence the evolution of cerebral hypoxic-ischemic damage by attenuating systemic PAF-induced hypotension under hypoxic conditions. Endothelial expression of PAF in posthypoxicischemic CNS tissue might also contribute to the development of hypoxic-ischemic brain damage by attracting and activating circulating neutrophils $(41,42)$. However, treatment with the systemically active PAF receptor antagonist WEB 2170 before the induction of hypoxia-ischemia in 7-d-old rats attenuated cerebral edema $42 \mathrm{~h}$ after the insult, but had no effect on the ultimate expression of damage $7 \mathrm{~d}$ after the insult (43). Unlike BN 52021 and BN 50730, which are both lipophilic and presumed to cross the blood-brain barrier, WEB 2170 is water soluble and does not cross the blood-brain barrier (43). This finding, together with our results, suggests that systemic or cerebral vascular mechanisms contribute little to the tissue effects of PAF in this neonatal cerebral hypoxia-ischemia model.

In conclusion, the present study adds support to the hypothesis that PAF is a mediator of hypoxic-ischemic damage in the immature rat brain. The mechanisms linking PAF to tissue damage could be both inflammatory and noninflammatory; these downstream mediators remain to be elucidated. However, accumulating evidence suggests that PAF exerts its damaging effects in the immature CNS at the parenchymal level, i.e. on neurons or microglia, rather than on the endothelium or circulating leukocytes. Our demonstration of a causal link between this mediator and perinatal brain injury complements the growing body of epidemiologic and human neuropathologic data suggesting a critical role for inflammatory mediators in perinatal brain injury. Future investigations should focus on elucidating neuronal and microglial mechanisms of injury that might be induced by PAF in the immature brain.
Acknowledgments. The authors thank Alicia Crossland, Hien Duong, and Deborah Kwon for valuable technical assistance and Dr. F.S. Silverstein for constructive comments.

\section{REFERENCES}

1. Yue TL, Lysko PG, Feuerstein G 1990 Production of platelet-activating factor from rat cerebellar granule cells in culture. J Neurochem 54:1809-1811

2. Jaranowska A, Bussolino F, Sogos V, Arese M, Lauro GM, Gremo F 1995 Plateletactivating factor production by human fetal microglia: effect of lipopolysaccharides and tumor necrosis factor- $\alpha$. Mol Chem Neuropathol 24:95-106

3. Mori M, Aihara M, Kume K, Hamanoue M, Kohsaka S, Shimizu T 1996 Predominant expression of platelet-activating factor receptor in the rat brain microglia. J Neurosci $16: 3590-3600$

4. Brodie C 1994 Functional PAF receptors in glia cells: binding parameters and regulation of expression. Int J Dev Neurosci 12:631-640

5. Predescu D, Ihida K, Predescu S, Palade GE 1996 The vascular distribution of the platelet-activating factor receptor. Eur J Cell Biol 69:86-98

6. Bazan NG 1998 The neuromessenger platelet-activating factor in plasticity and neurodegeneration. Prog Brain Res 118:281-291

7. Clark GD, McNeil RS, Bix GJ, Swann JW 1995 Platelet-activating factor produces neuronal growth cone collapse. Neuroreport 6:2569-2575

8. Bonavida B, Mencia-Huerta JM 1994 Platelet-activating factor and the cytokine network in inflammatory processes. Clin Rev Allergy 12:381-395

9. Nishida K, Markey SP 1996 Platelet-activating factor in brain regions after transient ischemia in gerbils. Stroke 27:514-518

10. Kumar R, Harvey SA, Kester M, Hanahan DJ, Olson MS 1988 Production and effects of platelet-activating factor in the rat brain. Biochim Biophys Acta 963:375-383

11. Pettigrew LC, Meyer JJ, Craddock SD, Butler SM, Tai HH, Yokel RA 1995 Delayed elevation of platelet activating factor in ischemic hippocampus. Brain Res 691:243247

12. Akisu M, Kultursay N, Coker I, Huseyinov A 1998 Platelet-activating factor is an important mediator in hypoxic ischemic brain injury in the newborn rat: flunarizine and Ginkgo biloba extract reduce PAF concentration in the brain. Biol Neonate 74:439-444

13. Panetta T, Marcheselli VL, Braquet P, Spinnewyn B, Bazan NG 1987 Effects of a platelet activating factor antagonist (BN 52021) on free fatty acids, diacylglycerols, polyphosphoinositides and blood flow in the gerbil brain: inhibition of ischemiareperfusion induced cerebral injury. Biochem Biophys Res Commun 149:580-587

14. Prehn JHM, Krieglstein J 1993 Platelet-activating factor antagonists reduce excitotoxic damage in cultured neurons from embryonic chick telencephalon and protect the rat hippocampus and neocortex from ischemic injury in vivo. J Neurosci Res 34:179-188

15. Bielenberg GW, Wagener G, Beck T 1992 Infarct reduction by the platelet activating factor antagonist apafant in rats. Stroke 23:98-103

16. Hofer RE, Christopherson TJ, Scheithauer BW, Milde JH, Lanier WL 1993 The effect of a platelet activating factor antagonist (BN 52021) on neurologic outcome and histopathology in a canine model of complete cerebral ischemia. Anesthesiology 79:347-353

17. Liu XH, Eun BL, Silverstein FS, Barks JDE 1996 The platelet-activating factor antagonist BN 52021 attenuates hypoxic-ischemic brain injury in the immature rat Pediatr Res 40:797-803

18. Marcheselli VL, Rossowska MJ, Domingo MT, Braquet P, Bazan NG 1990 Distinct platelet-activating factor binding sites in synaptic endings and in intracellular membranes of rat cerebral cortex. J Biol Chem 265:9140-9145

19. Nelson KB, Dambrosia JM, Grether JK, Phillips TM 1998 Neonatal cytokines and coagulation factors in children with cerebral palsy. Ann Neurol 44:665-675

20. Silverstein FS, Barks JDE, Hagan P, Liu X-H, Ivacko J, Szaflarski J 1997 Cytokines and perinatal brain injury. Neurochem Int 30:375-383

21. Wood PL 1995 Microglia as a unique cellular target in the treatment of stroke: potential neurotoxic mediators produced by activated microglia. Neurol Res 17:242248

22. Du ZY, Li XY 1998 Effects of ginkgolides on interleukin-1, tumor necrosis factor- $\alpha$ and nitric oxide production by rat microglia stimulated with lipopolysaccharides in vitro. Arzneimittelforschung 48:1126-1130

23. Righi M, Letari O, Sacerdote P, Marangoni F, Miozzo A, Nicosia S 1995 mycImmortalized microglial cells express a functional platelet-activating factor receptor. J Neurochem 64:121-129

24. Trescher WH, Ishiwa S, Johnston MV 1997 Brief post-hypoxic-ischemic hypothermia markedly delays neonatal brain injury. Brain Dev 19:326-338

25. Rice JE, Vannucci RC, Brierley JB 1981 The influence of immaturity on hypoxicischemic brain damage in the rat. Ann Neurol 9:131-141

26. Towfighi J, Yager JY, Housman C, Vannucci RC 1991 Neuropathology of remote hypoxic-ischemic damage in the immature rat. Acta Neuropathol (Berl) 81:578-587

27. Mujsce DJ, Christensen MA, Vannucci RC 1990 Cerebral blood flow and edema in perinatal hypoxic-ischemic brain damage. Pediatr Res 27:450-453

28. Dobbing J, Sands J 1979 Comparative aspects of the brain growth spurt. Early Hum Dev 3:79-83

29. Romijn HJ, Hofman MA, Gramsbergen A 1991 At what age is the developing cerebral cortex of the rat comparable to that of the full-term human baby? Early Hum Dev 26:61-67

30. McIlwain H, Bachelard HS 1985 Methods for the counting of neurons. In: McIlwain $\mathrm{H}$, Bachelard HS (eds) Biochemistry and the Central Nervous System. Churchill Livingstone, Edinburgh, pp 371-412 
31. Marcheselli VL, Bazan NG 1994 Platelet-activating factor is a messenger in the electroconvulsive shock-induced transcriptional activation of $c$-fos and zif-268 in hippocampus. J Neurosci Res 37:54-61

32. Singh N, Sharma A, Singh M 1997 Effects of BN-50730 (PAF receptor antagonist) and physostigmine (AChE inhibitor) on learning and memory in mice. Methods Find Exp Clin Pharmacol 19:585-588

33. Koltai M, Braquet PG 1994 Platelet-activating factor antagonists. Clin Rev Allergy 12:361-380

34. Konigsmark BW 1970 Chemical and enzymatic makeup of the brain during development and aging. In: Nauta WJH, Ebbesson SOE (eds) Contemporary Research Methods in Neuroanatomy. Springer, New York, pp 315-340

35. McDonald JW, Roeser NF, Silverstein FS, Johnston MV 1989 Quantitative assessment of neuroprotection against NMDA-induced brain injury. Exp Neurol 106:289296

36. Paxinos G, Watson C 1982 The Rat Brain in Stereotaxic Coordinates. Academic Press, New York

37. Morris RGM, Garrud P, Rawlins JNP, O'Keefe J 1982 Place navigation impaired in rats with hippocampal lesions. Nature 297:681-683
38. Bona E, Hagberg H, Loberg EM, Bagenholm R, Thoresen M 1998 Protective effects of moderate hypothermia after neonatal hypoxia-ischemia: short- and long-term outcome. Pediatr Res 43:738-745

39. Maclennan K, Smith PF, Darlington CL 1996 The effects of ginkgolide B (BN52021) on guinea pig vestibular nucleus neurons in vitro: importance of controlling for effects of dimethylsulphoxide (DMSO) vehicles. Neurosci Res 26:395-399

40. Kolb B, Tomie JA 1988 Recovery from early cortical damage in rats. Behav Brain Res 28:259-274

41. Hudome S, Palmer C, Roberts RL, Mauger D, Housman C, Towfighi J 1997 The role of neutrophils in the production of hypoxic-ischemic brain injury in the neonatal rat. Pediatr Res 41:607-616

42. Park TS, Gonzales ER, Gidday JM 1999 Platelet-activating factor mediates ischemiainduced leukocyte-endothelial adherence in newborn pig brain. J Cereb Blood Flow Metab 19:417-424

43. Viswanath M, Palmer C, Roberts RL 2000 Reduction of hypoxic ischemic brain swelling in the neonatal rat with PAF antagonist WEB2170: lack of long-term protection. Pediatr Res 48:109-113 